\title{
Hubungan Kepatuhan Antenatal Care $(A N C)$ dan Dukungan Suami dengan Kelancaran Persalinan di Desa Bulu Allapporenge Kecamatan Bengo Kabupaten Bone
}

\author{
St. Malka ${ }^{1 *}$ \\ 1. Akbid Batari Toja, Jl. Poros Majang No. 17, Watampone, Indonesia, Kode pos 92731 \\ *e-mail : st.malka@bataritoja.ac.id/085239309173
}

(Received : 24-07-2019; Reviewed : 20-08-2019; Accepted : 27-08-2019)

\begin{abstract}
ANC examination for pregnant women aims to detect abnormalities during pregnancy. If is quickly known it will be immediately resolved before effect on pregnancy by conducting and regular ANC examinations. Research objectives to determine ANC compliance and support husband with smooth childbirth in Bulu Allapporenge Village. The method this study used an analytical survey with Cross Sectional approach. The population was mothers who gave birth 24 months. The sampling technique used was purposive sampling of 46 people. Statistical using Chi Square with significant value $\alpha=0.05$ was obtained from the calculation with $\rho$ value 0.00, meaning that there is a relationship between ANC compliance and husband's support with smooth chilbirth in Bulu Allapporenge Village. It is expected that mothers are more motivated to conduct ANC visits and are expected husband can at assisting the wife in the labor process so that it can help the process of smooth childbirth.
\end{abstract}

Keywords: ANC Compliance, Husband's Support, Smooth Childbirth

\begin{abstract}
Abstrak
Pemeriksaan ANC bagi ibu hamil bertujuan untuk mendeteksi kelainan-kelainan yang mungkin ada atau akan timbul selama kehamilan. Apabila cepat diketahui akan dapat segera diatasi sebelum berpengaruh tidak baik terhadap kehamilan dengan melakukan pemeriksaan ANC secara rutin dan teratur.Tujuan penelitian untuk mengetahui kepatuhan ANC dan dukungan suami dengan kelancaran persalinan di Desa Bulu Allapporenge.Metode penelitian ini menggunakan survey analitik dengan pendekatan Cross Sectional.Populasi penelitian dalam penelitian ini adalah ibu yang telah melahirkan $\leq 24$ bulan.Tehnik pengambilan sampel menggunakan purposive sampling sebanyak 46 orang.Uji statistik menggunakan Chi Square dengan nilai signifikan $\alpha=0,05$ diperoleh hasil perhitungan dengan nilai $\rho$ value 0,00 , artinya ada hubungan antara kepatuhan ANC dan dukungan suami dengan kelancaran persalinan di Desa Bulu Allapporenge.Diharapkan kepada ibu untuk lebih termotivasi melakukan kunjungan ANC dan diharapkan suami dapat mendampingi istri pada proses persalinan sehingga dapat membantu proses kelancaran persalinan.
\end{abstract}

Kata Kunci: Dukungan Suami, Kelancaran Persalinan, Kepatuhan ANC 


\section{Pendahuluan}

World Health Organization (WHO) telah membuat program-program untuk meningkatkan kesehatan manusia, diantaranya menurunkan Angka Kematin Ibu dan bayi. Program yang dicanangkan oleh WHO yaitu Sustainable Development Goals (SDGs) untuk tahun 2016-2030 menggantikan Millenium Development Goals (MDGs). Dalam bidang kesehatan angka kematian ibu menjadi salah satu sorotan utama dalam target SDGs (Kemenkes 2016).

Faktor yang berkontribusi terhadap kematian ibu, secara garis besar dapat dikelompokkan menjadi dua penyebab, yaitu langsung dan penyebab tidak langsung. Penyebab langsung kematian ibu adalah faktor yang berhubungan dengan komplikasi kehamilan, persalinan, dan nifas seperti perdarahan, pre eklampsia/ eklampsia, infeksi, persalinan macet dan abortus. Penyebab tidak langsung kematian ibu adalah faktor-faktor yang memperberat keadaan ibu hamil seperti "empat terlalu" (terlalu muda, terlalu tua, terlalu sering melahirkan dan terlalu dekat jarak kelahiran), maupun yang mempersulit proses penanganan kedaruratan kehamilan, persalinan dan nifas seperti "tiga terlambat" (terlambat mengenali tanda bahaya dan mengambil keputusan, terlambat mencapai fasilitas kesehatan dan terlambat dalam penanganan kegawatdaruratan). Tanda bahaya kehamilan adalah tanda atau gejala yang menunjukkan ibu atau bayi yang dikandungnya dalam keadaan bahaya. Tanda bahaya kehamilan jika tidak terdeteksi akan menyebabkan kematian pada Ibu dan janin (Syafrudin, 2009).

Upaya-upaya yang dilakukan untuk mengendalikan angka kematian ibu dan bayi dilaksanakan seperti usaha pemeliharaan dan pengawasan antenatal sedini mungkin, serta persalinan yang aman dan perawatan masa nifas yang baik. Didalam kehamilan diperlukan pengawasan dan pemeriksaan secara teratur atau dikenal dengan Antenatal Care (ANC) (Sarinah, 2017).

Menurut World Health Organization (WHO) Antenatal Care (ANC) adalah untuk mendeteksi dini terjadinya resiko tinggi terhadap kehamilan dan persalinan juga dapat menurunkan angka kematian ibu dan memantau keadaan janin. Pemeriksaan ANC bagi ibu hamil bertujuan untuk mendeteksi kelainan-kelainan yang mungkin ada atau akan timbul pada kehamilan tersebut. Apabila cepat diketahui akan dapat segera diatasi sebelum berpengaruh tidak baik terhadap kehamilan dengan melakukan pemeriksaan ANC. (Winkjosastro, 2010).

Antenatal care atau pemeriksaan kehamilan merupakan salah satu tahapan penting yang harus dilakukan oleh ibu hamil menuju kehamilan yang sehat. Pemeriksaan kehamilan dapat dilakukan melalui dokter kandungan atau bidan kepada ibu hamil selama masa kehamilannya, yang mengikuti pedoman pelayanan antenatal yang diutamakan pada kegiatan promotif. Setiap wanita hamil menghadapi risiko komplikasi yang bisa mengancam jiwanya. Oleh karena itu setiap wanita hamil memerlukan sedikitnya 4 kali kunjungan selama periode antenatal yaitu satu kali kunjungan selama trimester pertama (sebelum 14 minggu), satu kali kunjungan selama trimester kedua (antara minggu 14-28) dan dua kali kunjungan selama trimester ketiga (antara minggu 28-36 dan sesudah minggu 36) (Prawirohardjo, 2010).

Pemanfaatan pelayanan ANC oleh seorang ibu hamil dapat dilihat dari cakupan pelayanan ANC. Cakupan pelayanan antenatal dapat dipantau melalui cakupan pelayanan K1 dan K4. Cakupan K1 adalah cakupan ibu hamil yang mendapatkan pelayanan ANC sesuai standar yang pertama kali pada masa kehamilan dan tidak tergantung usia kehamilan (K1), sedangkan cakupan kunjungan ibu hamil K4 adalah cakupan ibu hamil yang telah memperoleh pelayanan ANC sesuai standar paling sedikit 4 kali disatu wilayah kerja pada kurun waktu tertentu. Ibu hamil dianjurkan untuk melakukan pengawasan antenatal setidaknya sebanyak 4 kali (Usman, Nur Ulfa Damayanti Suherman dan Ayu Dwi Putri Rusman, 2018).

Kematian maternal dan kematian perinatal merupakan cerminan kemampuan dalam memberikan pelayanan kesehatan di tengah masyarakat. Setiap hari, sekitar 830 wanita meninggal karena sebab yang dapat dicegah terkait dengan kehamilan dan persalinan. Pada saat ini Angka Kematian Ibu (AKI) di Indonesia masih sangat tinggi. Angka kematian ibu mencapai 305 per 100.000 kelahiran hidup (Profil Kesehatan Indonesia,2017). Tahun 2015 jumlah kematian ibu yang dilaporkan menjadi 149 orang atau 99.38 per 100.000 kelahiran hidup, terdiri dari kematian ibu hamil 19 orang (12,75\%), kematian ibu bersalin 44 orang $(29,53 \%)$, kematian ibu nifas 86 orang $(57,71 \%)$, adapun kematian ibu menurut umur yaitu <20 tahun sebanyak 21 orang, umur 20-34 tahun sebanyak 83 orang, dan $\geq 35$ tahun sebanyak 45 orang (Profil Kesehatan Prov.Sul-Sel 2016). Kematian Ibu di Kabupaten Bone pada tahun 2018 sebanyak 8 orang (Dinkes Kab.Bone,2019)

Menurut Profil Kesehatan Indonesia Tahun 2018, Jumlah ibu bersalin di Indonesia sebanyak 5.043.078 orang, yang ditolong tenaga kesehatan di Fasilitas Pelayanan Kesehatan sebanyak 4.351.389 orang (86,28\%). Di Sulawesi Selatan jumlah ibu bersalin sebanyak 177.667 orang, yang ditolong tenaga kesehatan di fasilitas pelayanan kesehatan sebanyak 147.392 orang $(82,96 \%)$.

Dukungan keluarga merupakan bantuan sokongan yang diterima salah satu anggota keluarga dari anggota keluarga lainnya dalam rangka menjalankan fungsi-fungsi yang terdapat di dalam sebuah keluarga, dalam hal ini adalah dukungan yang diberikan suami/keluarga dalam pengambilan keputusan untuk menggunakan pelayanan kesehatan. Kehadiran suami tanpa tekanan dari luar, pada proses persalinan akan sangat penting dalam membantu istri terutama jika suami tahu banyak tentang proses persalinan. Para suami sering mengeluhkan 
betapa tertekannya mereka karena sama sekali tidak tahu apa yang harus dikerjakan untuk menolong istrinya (Sholihah, 2004).

Dalam setiap kunjungan ANC, selain pemeriksaan fisik, ibu akan mendapatkan informasi/pendidikan kesehatan tentang perawatan kehamilan yang baik, persiapan menjelang persalinan yang akan dihadapi nanti. Dengan demikian, ibu diaharapkan dapat lebih siap dan lebih percaya diri dalam menghadapi proses persalinan. Untuk itu, selama hamil hendaknya ibu memeriksakan kehamilannya secara teratur ke petugas kesehatan. (Herawati Mansur,2014). Fenomena psikologis yang menyertai proses persalinan bermacam-macam. Setiap wanita biasanya memiliki disposisi kepribadian yang definitif dan mewarnai persalinan bayinya. Perubahan psikologis keseluruhan wanita yang sedang mengalami persalinan, tergantung pada persiapan dan bimbingan dan antisipasi yang ia terima selama persiapan menghadapi persalinan, dukungan yang diterima wanita dari pasangannya, keluarga dan pemberi perawatan, lingkungan tempat wanita tersebut berada dan apakah bayi yang dikandungnya merupakan bayi yang diinginkan atau tidak. (Ai Yeyeh Rukiyah, 2009).

Menurut Robbins dan Judge (2010) mengemukakan bahwa sikap ibu melakukan ANC dipengaruhi oleh karakteristik pribadi (kepribadian, motif, minat, kebutuhan, pengalaman masa lalu dan harapan seseorang) dan situasi (waktu, keadaan kerja dan keadaan sosial), sedangkan faktor lain yaitu tenaga bidan kurang respon terhadap keluhan pasien terutama pada saat pasien tidak bisa lagi ke sarana pelayanan, keterbatasan fasilitas yang dimiliki polindes. Kondisi tersebut yang mempengaruhi persepsi ibu negatif sehingga ibu tidak yakin untuk melakukan ANC. Selain itu, anggapan ibu tentang kondisi kehamilan yang baik-baik saja sehingga ibu tidak perlu melakukan pemeriksaan kehamilan ke petugas kesehatan yang dapat berdampak pada meningkatnya angka kematian ibu hamil karena kurangnya deteksi dini resiko tinggi (Winaryati, 2009). Beberapa faktor yang mempengaruhi keaktifan ibu dalam melakukan kunjungan ANC yaitu umur, pendidikan, paritas dan pekerjaan (Yanti Missa, 2017).

\section{Metode}

Metode penelitian yang digunakan dalam penelitian ini adalah analitik dengan pendekatan waktu cross sectional, menggunakan teknik purposive sampling. Populasi penelitian ini adalah ibu yang telah melahirkan $\leq$ 24 bulan yang lalu di Desa Bulu Allapporenge kecamatan Bengo Kabupaten Bone tahun 2019. Sampel dalam penelitian ini adalah ibu yang telah melahirkan $\leq 24$ bulan yang lalu di Desa Bulu Allapporenge kecamatan Bengo Kabupaten Bone tahun 2019 dan teknik pengambilan sampel purposive sampling non random yang memenuhi kriteria inklusi dan kriteria eksklusi sebanyak 46 orang.

Pengumpulan data dilakukan melalui wawancara langsung dengan responden dengan menggunakan kuesioner yang berisi tentang karakteristik responden, kelancaran persalinan, kepatuhan ANC dan dukungan suami. Analisis data menggunakan komputer dengan uji Chi Square dengan tingkat kepercayaan 95\% (P <0,05) untuk melihat hubungan antara variabel dependen (kelancaran persalinan) dan variabel independen (Kepatuhan ANC dan dukungan suami).

\section{Hasil}

1. Analisis Univariat

Tabel 1. Karakteristik Responden Berdasarkan Kelancaran Persalinan Di Desa Bulu Allapporenge

\begin{tabular}{lcc}
\hline \multicolumn{1}{c}{ Karakteristik } & Frekuensi & Persentase (\%) \\
\hline Kelancaran Persalinan & & \\
Lancar & 41 & 89,1 \\
Tidak Lancar & 5 & 10,9 \\
Jumlah & 46 & 100 \\
Kepatuhan ANC & & \\
Patuh & 38 & 82,6 \\
Tidak Patuh & 8 & 17,4 \\
Jumlah & 46 & 100 \\
Dukungan Suami & & \\
Mendukung & 35 & 76,1 \\
Tidak Mendukung & 11 & 23,9 \\
Jumlah & 46 & 100 \\
\hline
\end{tabular}

Berdasarkan tabel 1. dapat diketahui bahwa dari 46 jumlah responden di Desa Bulu Allapporenge terdapat 5 orang $(10,9 \%)$ yang proses persalinannya tidak lancer, 38 orang $(82,6 \%)$ yang patuh dalam 
melakukan kunjungan dan 35 orang $(76,1 \%)$ yang mendapatkan dukungan dari suami pada saat proses persalinan.

2. Analisis Bivariat

Tabel 2. Hubungan Kepatuhan Anc Dengan Kelancaran Persalinan Di Desa Bulu Allapporenge

\begin{tabular}{|c|c|c|c|c|c|c|c|c|c|}
\hline \multirow{3}{*}{$\begin{array}{c}\text { Kepatuhan } \\
\text { ANC }\end{array}$} & \multicolumn{4}{|c|}{ Kelancaran Persalinan } & \multirow{2}{*}{\multicolumn{2}{|c|}{ Total }} & \multirow{3}{*}{$P$ Value } & \multirow{2}{*}{\multicolumn{2}{|c|}{$95 \% \mathrm{C}$}} \\
\hline & \multicolumn{2}{|c|}{ Lancar } & \multicolumn{2}{|c|}{ Tidak Lancar } & & & & & \\
\hline & $\mathbf{n}$ & $\%$ & $\mathbf{n}$ & $\%$ & $\mathbf{n}$ & $\%$ & & Lower & Upper \\
\hline Patuh & 37 & 80,4 & 1 & 2,2 & 38 & 82,6 & & & \\
\hline Tidak Patuh & 4 & 8,7 & 4 & 8,7 & 8 & 17,4 & 0,00 & 3,284 & 416,924 \\
\hline Jumlah & 41 & 89,1 & 5 & 10,9 & 46 & 100 & & & \\
\hline
\end{tabular}

Berdasarkan tabel diatas dapat diketahui bahwa dari 46 jumlah responden di Desa Bulu Allapporenge terdapat 37 orang $(80,4 \%)$ yang patuh melakukan kunjungan ANC dan lancar dalam proses persalinannya, 1 orang $(2,2 \%)$ yang patuh melakukan kunjungan ANC dan tidak lancar dalam proses persalinannya. Jadi jumlah responden yang patuh melakukan kunjungan ANC sebanyak 38 orang (82,6\%). Jumlah responden yang tidak patuh melakukan kunjungan ANC dan lancar dalam proses persalinannya sebanyak 4 orang $(8,7 \%)$ dan terdapat 4 orang $(8,7 \%)$ yang tidak patuh dan tidak lancar dalam proses persalinannya.

Dari uji statistic diperoleh nilai $\rho$ value $<0,05$ yaitu 0,00 yang berarti ada hubungan antara kepatuhan ANC dengan kelancaran persalinan dan Ha diterima.

Tabel 3. Hubungan Dukungan Suami Dengan Kelancaran Persalinan Di Desa Bulu Allapporenge

\begin{tabular}{|c|c|c|c|c|c|c|c|c|c|}
\hline \multirow{3}{*}{$\begin{array}{c}\text { Dukungan } \\
\text { Suami }\end{array}$} & \multicolumn{4}{|c|}{ Kelancaran Persalinan } & \multirow{2}{*}{\multicolumn{2}{|c|}{ Total }} & \multirow{3}{*}{$P$ Value } & \multirow{2}{*}{\multicolumn{2}{|c|}{$95 \% C I$}} \\
\hline & \multicolumn{2}{|c|}{ Lancar } & \multicolumn{2}{|c|}{ Tidak Lancar } & & & & & \\
\hline & $\mathbf{n}$ & $\%$ & $\mathbf{n}$ & $\%$ & $\mathbf{n}$ & $\%$ & & Lower & Upper \\
\hline Mendukung & 35 & 76,1 & 0 & 0 & 35 & 76,1 & \multirow{3}{*}{0,00} & \multirow{3}{*}{1,069} & \multirow{3}{*}{3,144} \\
\hline Tidak Mendukung & 6 & 13,0 & 5 & 10,9 & 11 & 23,9 & & & \\
\hline Jumlah & 41 & 89,1 & 5 & 10,9 & 46 & 100 & & & \\
\hline
\end{tabular}

Berdasarkan tabel hubungan dukungan suami dengan kelancaran persalinan diatas dapat diketahui bahwa dari 46 jumlah responden di Desa Bulu Allapporenge terdapat 35 orang $(76,1 \%$ ) yang mendapatkan dukungan suami dan lancar dalam proses persalinannya. terdapat 6 orang $(13,0 \%)$ yang tidak mendapatkan dukungan dan lancar dalam proses persalinanya, 5 orang $(10,9 \%)$ yang tidak mendapatkan dukungan dan tidak lancar dalm proses persalinannya.

Dari uji statistic diperoleh nilai $\rho$ value $<0,05$ yang berarti ada hubungan antara dukungan suami dengan kelancaran persalinan dan Ha diterima.

\section{Pembahasan}

1. Hubungan Kepatuhan ANC Dengan Kelancaran Persalinan di Desa Bulu Allapporenge

Kepatuhan merupakan perilaku yang dapat diobservasi, dengan demikian dapat segera diukur. Kepatuhan mengacu pada kemampuan untuk mempertahankan program-program yang berkaitan dengan promosi kesehatan yang sebagian besar ditentukan oleh penyelenggara perawatan kesehatan (Sumarah, 2009).

Antenatal Care sebagai salah satu upaya pencegahan awal dari faktor risiko kehamilan. Pelayanan antenatal adalah pelayanan kesehatan oleh tenaga kesehatan untuk ibu semasa kehamilannya, dilaksanakan sesuai dengan standar pelayanan antenatal yang ditetapkan dalam standar pelayanan kebidanan. Pelayanan antenatal sesuai standar meliputi anamnesis, pemeriksaan fisik (umum dan kebidanan), pemeriksaan laboratorium atas indikasi, serta intervensi dasar dan khusus. Pelaksanan antenatal dikatakan baik atau tidak bila ibu yang melakukan kunjungan antenatal sesuai dengan jumlah kunjungan antenatal yaitu pada trimester I minimal melakukan 1 kali kunjungan, pada trimester II minimal melakukan 1 kali kunjungan dan pada trimester III minimal melakukan 2 kali kunjungan (Siringo-ringo, 2012).

Pemeriksaan kehamilan yang tidak teratur akan berpengaruh pada kondisi ibu dan bayi, karena kurang terpantaunya keadaan ibu sehingga bila terjadi masalah tidak dapat ditangani secara dini dan berakibat terjadinya kehamilan beresiko yang diikuti proses persalinan patologis. Tentu hal ini bisa berdampak pada peningkatan AKI dan AKB. Oleh karena itu diperlukan asuhan kebidanan yang berkesinambungan 
(continuity of care) dengan melibatkan keluarga, agar ibu meperoleh asuhan secara maksimal selama hamil, bersalin dan masa nifas. (Rodiyatun, Anis Nur Laili, Vicky Ambar Rachmawati, 2018).

Ibu hamil yang patuh melakukan kunjungan ANC akan memperoleh kemudahan untuk mendapatkan informasi mengenai pentingnya menjaga kehamilan, memperoleh bantuan secara profesional apabila mendapat masalah dalam proses kehamilannya, dan mendapatkan pelayanan kesehatan, sehingga ibu terdorong untuk melakukan kunjungan kehamilan secara teratur. Ibu diharapkan dapat memanfaatkan sebaik-baiknya fasilitas kesehatan, karena ibu yang patuh dalam melakukan kunjungan ANC selain mendapat informasi mengenai pentingnya menjaga kehamilan, ibu dapat memantau pertumbuhan dan perkembangan janin, sehingga gizi ibu maupun janin dapat terpantau dengan baik. Menurut Manuaba, pengawasaan ANC yang sesuai standart dan teratur dapat memberikan manfaat dengan ditemukannya berbagai kelainan yang menyertai kehamilan secara dini, sesuai dengan tujuan dari ANC yaitu untuk memantau kemajuan kehamilan, untuk memastikan kesehatan ibu dan tumbuh kembang janin, meningkatkan dan mempertahankan kesehatan fisik, mental dan sosial ibu dan janin, mengenali secara dini adanya ketidak lancaran/ komplikasi yang mungkin terjadi selama hamil, termasuk riwayat penyakit secara umum, mempersiapkan persalinan cukup bulan, melahirkan dengan selamat, ibu maupun bayinya dengan trauma seminimal mungkin, memersiapkan peran ibu dan keluarga dalam menerima kelahiran agar dapat tumbuh kembang secara lancar, menurunkan angka kematian ibu dan prinatal. (Nuris, Kushayati, 2010).

Asuhan antenatal ini dilakukan dengan cara mengumpulkan data menetapkan diagnose rencana tindakan dan melaksanakannya untuk menjamin keamanan dan keleluasaan serta kesejahteraan janin selama periode kehamilan terutama pada pemeriksaan antenatal pertama ataupun ulangan. Sesuai dengan kebijakan Departemen Kesehatan, standar minimal pelayanan pada ibu hamil adalah tujuh bentuk yang disingkat $7 \mathrm{~T}$ yaitu: Timbang dan ukur tinggi badan, ukur tekanan darah, ukur tinggi fundus uteri, pemberian imunisasi tetanus toxoid lengkap, pemberian tablet besi (Fe) minimal 90 tablet selama kehamilan dengan dosis satu tablet setiap harinya, lakukan tes penyakit menular seksual (PMS), temu wicara dalam rangka persiapan rujukan Dampak dari ibu hamil yang tidak mengikuti ANC adalah meningkatnya angka mortalitas dan morbilitas ibu, tidak terdeteksinya kelainan-kelainan kehamilan dan kelainan fisik yang terjadi pada saat persalinan tidak dapat di deteksi secara dini. Selain itu ibu hamil kurang mendapatkan informasi tentang persiapan persalinan sehingga pada saat akan menghadapi persalinan kecemasannya meningkat. (Missa M. Yanti, Ahmad Nuh Khori, Shanti Rosmaharani, 2017).

Perasaan cemas yang seringkali menyertai kehamilan akan mencapai puncaknya pada saat persalinan. Persalinan merupakan suatu pengalaman yang membutuhkan kerja keras dan perjuangan yang melelahkan bagi ibu. Bayangan resiko akan kematian ketika melahirkan semakin mempengaruhi kestabilan emosi ibu. Jika kondisi emosi yang tidak stabil ini dibawa terus sampai pada proses persalinan, dapat menyebabkan persalinan tidak lancar. Selain itu, banyak ibu yang merasakan sakit saat bersalin lebih parah dari seharusnya karena banyak oleh rasa panik dan stress (Missa M. Yanti, Ahmad Nuh Khori, Shanti Rosmaharani, 2017).

Hasil penelitian ini sejalan dengan hasil penelitian Andrias Puji Laksono, dkk tahun 2018 yang menyatakkkan bahwa ada hubungan kepatuhan kunjungan ANC dengan kejadian persalinan normal di Puskesmas Bangetayu Semarang. Namun hasil penelitian ini berbeda dengan hasil penelitian Farrah Rianda Usman,dkk, tahun 2016 yang menyatakan bahwa tidak ada perbedaan tingkat kecemasan ibu hamil menghadapi persalinan dengan kepatuhan ANC.

Pemeriksaan ANC yang tidak rutin atau yang belum optimal dapat mengakibatkan resiko dan komplikasi kehamilan tidak terdeteksi secara dini, ibu juga tidak akan mendapatkan informasi mengenai pentingnya menjaga kehamilan, serta ibu tidak dapat memantau pertumbuhan dan perkembangan janin, begitu juga gizi ibu maupun janin tidak dapat terpantau dengan baik, sehingga kemungkinan untuk bersalin normal berkurang (Handiani \& Purwanti, 2012).

Penelitian yang dilakukan oleh Suwanti (2014) menyebutkan bahwa ada hubungan antara frekuensi kunjungan ANC dengan pemilihan penolong persalinan karena semakin sering ibu melakukan kunjungan ANC maka lebih mengetahui kondisi kehamilannya serta dapat memilih tenaga kesehatan yang akan menolong saat persalinannya nanti. Penelitian yang dilakukan oleh Sulastri (2014) mengatakan bahwa kunjungan antenatal yang baik dan rutin dapat mendeteksi secara dini komplikasi yang mungkin muncul selama kehamilan, dalam hal ini membuktikan bahwa kunjungan antenatal yang tidak adekuat selama kehamilan menjadi faktor dominan persalinan sectio caesarea. Penelitian Utami (2013), menyebutkan tidak ada hubungan antara kunjungan ANC dengan kelahiran prematur karena kualitas pelayanan ANC yang kurang optimal.

2. Hubungan Dukungan Suami Dengan Kelancaran Persalinan di Desa Bulu Allapporenge

Persalinan lama atau perpanjangan Kala II dapat diakibatkan oleh kecemasan atau ketegangan, rasa tidak aman dan kekhawatiran yang timbul karena dirasakan terjadi sesuatu yang tidak menyenangkan tapi sumbernya sebagian besar tidak diketahui dan berasal dari dalam (intra psikis) (Manuaba, 2010). Persalinan merupakan peristiwa yang sangat stres, kenaikan adrenalin dan cortisol yang lebih besar dari pada peningkatan nor adrenalin menunjukkan bahwa stres mental lebih besar dari pada stres fisik. Sekresi 
adrenalin dipengaruhi aktivitas mental: menyenangkan dan tidak menyenangkan, cortisol terutama distimuli oleh kuatnya stres emosional negatif misalnya takut, cemas (Alihagen dkk., 2005).

Proses persalinan selain dipengaruhi oleh faktor passage, passanger, power dan penolong, faktor psikis juga sangat menentukan keberhasilan persalinan. Dimana kecemasan atau ketegangan, rasa tidak aman dan kekhawatiran yang timbul karena dirasakan terjadi sesuatu yang tidak menyenangkan tapi sumbernya sebagian besar tidak diketahui dan berasal dari dalam (intra psikis) dapat mengakibatkan persalinan menjadi lama atau perpanjangan Kala II (Manuaba, 2010).

Berdasarkan teori naw nolan yang menyatakan bahwa ibu yang mendapat dukungan keluarga saat bersalin mengalami kelancaran persalinan karena ibu mendapatkan dukungan psikologi dan merasa nyaman. Dapat dilihat dari beberapa faktor yang membuat persalinan tidak lancar bisa disebabkan psikologi ibu, dan kurangnya pendampingan pada saat bersalin. Dukungan Suami/keluarga adalah proses yang terjadi terus menerus disepanjang masa kehidupan manusia. Dukungan suami merupakan suatu bentuk hubungan interpersonal yang meliputi sikap,tindakan dan penerimaan terhadap anggota keluarga, sehingga anggota keluarga merasa ada yang memperhatikan. Anggota keluarga memandang bahwa orang yang bersifat mendukung selalu siap memberikan pertolongan dan bantuan jika diperlukan (Fiedman, 2012).

Faktor psikologis ketakutan dan kecemasan sering menjadi penyebab lamanya persalinan, his menjadi kurang baik, pembukaan menjadi kurang lancar. Menurut Pritchard, dkk perasaan takut dan cemas merupakan faktor utama yang menyebabkan rasa sakit dalam persalinan dan berpengaruh terhadap kontraksi rahim dan dilatasi serviks sehingga persalinan menjadi lama.

Hasil penelitian di atas menunjukkan bahwa ada hubungan antara dukungan suami dengan kelancaran persalinan. Hasil penelitian tersebut sesuai teori Mary Nolan, 2010, saat sedang dalam kesulitan, sebagian orang akan meminta bantuan dan dukungan dari orang lain atau keluarga. sebagai orang dewasa terkadang hal itu tidak dilakukan dan dapat menerimanya sebagai suatu proses pendewasaan diri. Tetapi, pada saat sedang menjalani persalinan, waktunya kita memiliki seseorang untuk mendampingi dan mendukung kita. Tidak hanya persalinan yang dilakukan di rumah atau di rumah sakit, pendamping persalinan dibutuhkan untuk membantu seseorang bersikap rileks dan menambah kelancaran dalam proses persalinannya. Hal ini juga sejalan dengan penelitian yang dilakukan oleh Idawati dan Helmi Yenie di BPS Muksinin yang menunjukkan bahwa ibu yang tidak mendapat dukungan mempunyai peluang untuk mengalami persalinan tidak lancar dibandingkan dengan yang mendapat dukungan.

Berdasarkan hasil penelitian tersebut, ibu bersalin yang mendapat dukungan suami selama proses persalinan sebagian besar mengalami kelancaran persalinan dan merasa lebih tenang dan nyaman dalam menghadapi persalinan karena memiliki teman (pendukung persalinan) untuk berbagi rasa sakit dan cemas akan semua proses persalinan dan saat-saat menunggu kelahiran bayi mereka. Dengan demikian maka ada hubungan antara Ibu bersalin dengan dukungan suami dalam proses kelancaran persalinan. Untuk itu maka diharapkan tenaga kesehatan yang ada di lahan penelitian dapat meningkatkan pemberian konseling tentang pentingnya dukungan keluarga khususnya suami saat persalinan.

Dukungan yang terus menerus dari seorang pendamping persalinan kepada ibu selama proses persalinan dan melahirkan dapat mempermudah proses persalinan dan melahirkan, memberikan rasa nyaman, semangat, membesarkan hati ibu dan meningkatkan rasa percaya diri ibu, serta mengurangi kebutuhan tindakan medis.

\section{Kesimpulan}

Ada hubungan antara Kepatuhan ANC Dengan Kelancaran Persalinan di Desa Bulu Allapporenge dan Ada hubungan antara Dukungan Suami Dengan Kelancaran Persalinan di Desa Bulu Allapporenge. Untuk penelitian selanjutnya, disarankan untuk menggunakan metode lain dengan pemberian intervensi dan menggunakan sampel yang lebih banyak.

\section{Saran}

1. Keluarga

Diharapkan bagi keluarga terutama suami untuk memberikan dukungan dalam kepatuhan ANC terhadap kelancaran persalinan.

2. Puskesmas dan Petugas kesehatan

Diharapkan kepada puskesmas, dokter, perawat dan petugas kesehatan lainnya agar memberikan edukasi atau informasi tentang pentinganya tentang hal-hal yang berhubungan dengan perawatan di ANC.

3. Peneliti

Disarankan kepada peneliti agar meneliti variabel yang lain yang dianggap mampu mempengaruhi kepatuhan ANC bagi ibu hamil. 


\section{Ucapan Terima Kasih}

Perkenankan Penulis mengucapkan terimakasih kepada Ketua Yayasan Makassar Indonesia, dan Mahasiswa Akbid Batari Toja Watampone atas dukungan moral maupun tenaga yang diberikan.

\section{Referensi}

Andrias, P. L., Sri, R., Ernawati. 2018. Hubungan kepatuhan kunjungan ANC dengan cara perslinan normal di puskesmas bangetayu semarang, Universitas Muhammadiah Semarang

Dinkes Kabupaten Bone. 2019.

Farrah R. U., Rina M. K., Franly O. 2016. Perbedaan tingkat kecemasan ibu hamil menghadapi persalinan dengan kepatuhan Antenatal Care (ANC) di puskesmas bahu kota manado. ejournal Keperawatan (e-Kp) Volume 4 Nomor 1Februari 2016, Hal 1-7

Friedman. 2012. Keperawatan keluarga.Yogyakarta: Gosyen Publishing

Handiani, R. S., \& Purwanti, A. 2012. Motivasi dan Kepatuhan Kunjungan Antenatal Care (ANC) pada Ibu Hamil Trimester III. Jurnal Keperawatan, 183-188. Vol. 3, No. 2. ISSN: 2086-3071

Idawati, Helmi, Y. 2014. Dukungan Keluarga terhadap Kelancaran Proses Persalinan di BPS Muksinin.

Kristina, A. N. 2017. Hubungan dukungan suami dengan kepatuhan melakukan kunjungan anc pada ibu hamil tm III di Puskesmas Sasi Kabupaten Timor Tengah Utara.

Kemenkes RI. 2016. Profil Kesehatan Indonesia tahun 2015. Jakarta :

Kemenkes RI 2017. Profil Kesehatan Indonesia tahun 2016. Jakarta :

Mansur, Herawati, Temu, B. 2014. "Psikologi Ibu dan Anak untuk Kebidanan”. Jakarta : Selemba Medika.

Manuaba, Ida B. G. 2010,Ilmu kebidanan, Penyakit Kandungan dan Keluarga Berencana Untuk Pendidikan Bidan, EGC.

Meirita D. W. 2017. Hubungan dukungan suami dengan kepatuhan pemeriksaan Antenatal Care pada ibu hamil di puskesmas Kasihan II Bantul Yogyakarta

Missa, Yanti, Ahmad, N. K., Shanti, R. 2017. Jurnal Hubungan Kepatuhan Antenatal Care (ANC) Dengan Kecemasan Ibu Hamil Trimester III Dalam Menghadapi Persalinan Di Desa Sumbermulyo, Jogoroto Kabupaten Jombang".

Nolan, M. 2010. Kelas bersalin. Golden Books, yogyakarta

Prawirohardjo, S. 2010. Ilmu Kebidanan.Jakarta:Yayasan Bina Pustaka

Profil Kesehatan Provinsi Sulawesi Selatan Tahun 2016

Profil Kesehatan Indonesia tahun 2017,

Profil Kesehatan Indonesia tahun 2018,

Rodiyatun, A. N. L., Vicky A. R. 2018. Pengaruh Budaya Patriarki Terhadap Keteraturan Pemeriksaan Kehamilan Pada Ibu Hamil Di Wilayah Puskesmas Bangkalan

Rukiyah, A. Y. 2009. Asuhan Kebidanan I (Kehamilan). Jakarta : TIM.

Rukiyah, A. Y. 2009. Asuhan Kebidanan II (Persalinan). Jakarta : TIM.

Siringo, A. S. R. 2012. Pengetahuan ibu hamil dan motivasi keluarga dalam pelaksanaan antenatal care di puskesmas ujung batu riau. Jurnal Keperawatan Holistik,1(3). 
Solihah, Lutfiatus. 2004. Persiapan dan strategi menghadapi persalinan sahat dan alamiah. Jakarta. Diva Press.

Sumarah. 2009. Perawatan Ibu Bersalin :Asuhan Kebidanan Pada Ibu Bersalin. Yogyakarta: Fitramaya

Suwanti, Romiastuti, S., Chandradewi, A. 2014. Hubungan Frekuensi Antenatal Care (ANC) dengan Pemilihan Penolong Persalinan di Wilayah Kerja Puskesmas Moyo Hulu Kabupaten Sumbawa. Jurnal Kesehatan Prima. Vol.8, No.1

Sarinah. 2017. Hubungan pengetahuan ibu multigravida tentang kunjungan antenatal care dengan kejadian tanda bahaya kehamilan di kabupaten aceh tenggara, Jurnal ilmiah Maksitek Vol.2 (2) Halaman 120-133.

Usman, Nur U. D. S., Ayu D. P. R. 2018. Faktor Yang Berhubungan dengan Pemanfaatan Antenatal Care Di Puskesmas Madising Na Mario Kota Parepare.

Wiknjosastro, Hanifa. 2010. Ilmu Kandungan. Jakarta : Yayasan Bina Pustaka Sarwono Prawirohardj

Winaryati. 2009.Buku Ajar Konsep Kebidanan. Jakarta: EGC

World Health Organization, 16 February 2018, Maternal Mortality, https://www.who.int/news-room/factsheets/detail/maternal-mortality 